\title{
Article
}

\section{Impact of Adjuvant Radiotherapy in Patients with Central Neurocytoma: A Multicentric International Analysis}

\author{
Laith Samhouri ${ }^{1,+}{ }^{+}$, Mohamed A. M. Meheissen ${ }^{2,3,+}{ }^{-0}$, Ahmad K. H. Ibrahimi ${ }^{4}$, Abdelatif Al-Mousa ${ }^{4}$, \\ Momen Zeineddin ${ }^{5}$, Yasser Elkerm ${ }^{3,6}$, Zeyad M. A. Hassanein ${ }^{2,3}{ }^{\circledR}$, Abdelsalam Attia Ismail 2,3, \\ Hazem Elmansy ${ }^{3,6}$, Motasem M. Al-Hanaqta ${ }^{7}{ }^{\circ}$, Omar A. AL-Azzam ${ }^{8}$, Amr Abdelaziz Elsaid ${ }^{2,3}{ }^{\circ}$, \\ Christopher Kittel ${ }^{1}$, Oliver Micke ${ }^{9}$, Walter Stummer ${ }^{10}$, Khaled Elsayad ${ }^{1, *, \ddagger}$ and Hans Theodor Eich ${ }^{1, \ddagger}$
}

check for updates

Citation: Samhouri, L.; Meheissen, M.A.M.; Ibrahimi, A.K.H.; Al-Mousa,

A.; Zeineddin, M.; Elkerm, Y.;

Hassanein, Z.M.A.; Ismail, A.A.;

Elmansy, H.; Al-Hanaqta, M.M.; et al. Impact of Adjuvant Radiotherapy in Patients with Central Neurocytoma: A Multicentric International Analysis. Cancers 2021, 13, 4308. https:// doi.org/10.3390/cancers13174308

Academic Editor: Meritxell Arenas

Received: 5 August 2021

Accepted: 25 August 2021

Published: 26 August 2021

Publisher's Note: MDPI stays neutral with regard to jurisdictional claims in published maps and institutional affiliations.

Copyright: (c) 2021 by the authors. Licensee MDPI, Basel, Switzerland. This article is an open access article distributed under the terms and conditions of the Creative Commons Attribution (CC BY) license (https:// creativecommons.org/licenses/by/ $4.0 /)$.
1 Department of Radiation Oncology, University Hospital Münster, Münster 48149, Germany; laithsamhouri@gmail.com (L.S.); Christopher.Kittel@ukmuenster.de (C.K.); hans.eich@ukmuenster.de (H.T.E.)

2 Alexandria Clinical Oncology Department, Alexandria University, Alexandria 21500, Egypt; mohamed.meheissen@alexmed.edu.eg (M.A.M.M.); zeyadabdelaziz@hotmail.com (Z.M.A.H.); salam61@yahoo.com (A.A.I.); amrelsaid@yahoo.com (A.A.E.)

3 Specialized Universal Network of Oncology (SUN), Alexandria 21500, Egypt; yelkerm@yahoo.com (Y.E.); hazemelmansy@hotmail.com (H.E.)

4 Department of Radiotherapy and Radiation Oncology, King Hussein Cancer Center, Amman 11942, Jordan; aibrahimi@khcc.jo (A.K.H.I.); aalmousa@khcc.jo (A.A.-M.)

5 Department of Pediatrics, King Hussein Cancer Center, Amman 11942, Jordan; MZ.12765@khcc.jo

6 Cancer Management and Research Department, Medical Research Institute, Alexandria University, Alexandria 21500, Egypt

7 Military Oncology Center, Royal Medical Services, Amman 11942, Jordan; Drhanaqta@yahoo.com

8 Princess Iman Research Center, King Hussein Medical Center, Royal Medical Services, Amman 11942, Jordan; Omarazzam89@outlook.com

9 Department of Radiotherapy and Radiation Oncology, Franziskus Hospital Bielefeld, 33699 Bielefeld, Germany; Oliver.Micke@franziskus.de

10 Department of Neurosurgery, University Hospital Münster, 48149 Münster, Germany; Walter.Stummer@ukmuenster.de

* Correspondence: khaled.elsayad@uni-muenster.de; Tel.: +490-2518347384

$+\quad$ Laith Samhouri and Mohamed A.M. Meheissen contributed the first authorship equally to this work.

$\ddagger \quad$ Khaled Elsayad and Hans Theodor Eich contributed the senior authorship equally.

Simple Summary: Central neurocytoma is a rare tumor accounting for $<0.5 \%$ of all intracranial tumors. We analyzed 33 patients treated with surgical resection with or without radiotherapy from ten closely cooperating institutions in Germany, Egypt, and Jordan. Patients who received radiotherapy had longer progression-free survival with an acceptable toxicity profile.

Abstract: Background: Central neurocytoma $(\mathrm{CN})$ is a rare tumor accounting for $<0.5 \%$ of all intracranial tumors. Surgery \pm radiotherapy is the mainstay treatment. This international multicentric study aims to evaluate the outcomes of CNs patients after multimodal therapies and identify predictive factors. Patients and methods: We retrospectively identified 33 patients with $\mathrm{CN}$ treated between 2005 and 2019. Treatment characteristics and outcomes were assessed. Results: All patients with $\mathrm{CN}$ underwent surgical resection. Radiotherapy was delivered in 19 patients. The median radiation dose was 54 Gy (range, 50-60 Gy). The median follow-up time was 56 months. The 5-year OS and 5 -year PFS were $90 \%$ and $76 \%$, respectively. Patients who received radiotherapy had a significantly longer PFS than patients without RT ( $p=0.004)$ and a trend towards longer OS. In addition, complete response after treatments was associated with longer PFS ( $p=0.07)$. Conclusions: Using RT seems to be associated with longer survival rates with an acceptable toxicity profile.

Keywords: neurocytoma; toxicities; rare tumors; management; radiation therapy 


\section{Introduction}

Central neurocytoma $(\mathrm{CN})$ is a rare disease accounting for only $\leq 0.5 \%$ of all intracranial neoplasms originating from the ventricular space [1-3]. According to the recent World Health Organization (WHO) classification, CNs are classified as grade 2 and usually occur in young patients and adolescents, with a similar incidence between males and females [3,4]. Most CNs are well-differentiated and have a benign nature with favorable prognoses following the multimodal treatments $[3,4]$. However, malignant variants have been reported with an MIB-labeling index $>2 \%$ with a higher recurrence rate [5-7]. Surgical resection is the mainstay of treatment of NC; however, residual or recurrent $\mathrm{CNs}$ are challenging to manage. The most important prognostic factor affecting patients' outcomes is the extent of surgery $[8,9]$. The role of radiotherapy and chemotherapy remains controversial with a limited number of studies due to disease rarity.

This international multicenter study aims to evaluate the outcomes of CNs patients after multimodal therapies and identify other predictive factors which may influence the outcome.

\section{Patients and Methods}

Thirty-three patients with neurocytoma were collected between 2001 and 2019 from ten closely cooperating institutions in Germany, Egypt, and Jordan. Patient characteristics are summarized in Table 1. All patients with NC were presented in a multidisciplinary tumor board following surgery. After resection, almost all patients had received MRI $(\mathrm{n}=32)$ and CT $(n=33)$ to define any residuals. The planning target volume (PTV) represented a 5-10 $\mathrm{mm}$ of the clinical target volume, an anatomically constrained $10-15 \mathrm{~mm}$ expansion of the gross-residual tumor and tumor bed.

Table 1. Treatment characteristics and postoperative therapy.

\begin{tabular}{|c|c|c|c|c|}
\hline \multirow{2}{*}{ Characteristic } & \multirow{2}{*}{ Nr. (\% or Range) } & \multicolumn{3}{|c|}{ Therapy } \\
\hline & & Radiotherapy & No Radiotherapy & $p$-Value \\
\hline Patients & 33 & $19(58 \%)$ & $14(42 \%)$ & \\
\hline Med. age (range) & 25 y $(4-58)$ & $24(12-58)$ & $26(4-50)$ & 0.5 \\
\hline Sex & $\begin{array}{l}\text { M: } 17(51 \%) \\
\text { F: } 16(49 \%)\end{array}$ & $\begin{array}{c}9(47 \%) \\
10(53 \%)\end{array}$ & $\begin{array}{l}8(47 \%) \\
6(53 \%)\end{array}$ & 0.7 \\
\hline Ki67 MIB1 value, median & $8(1-30)$ & $7.5(1-30)$ & $10(1-25)$ & 0.8 \\
\hline Resection & & & & 0.02 \\
\hline Gross total resection & $9(27 \%)$ & $2(10 \%)$ & $7(50 \%)$ & \\
\hline Subtotal resection & $24(73 \%)$ & $17(90 \%)$ & $7(50 \%)$ & \\
\hline Chemotherapy & & & & 0.2 \\
\hline Yes & $2(6 \%)$ & $0(0 \%)$ & $2(14 \%)$ & \\
\hline No & $31(94 \%)$ & $19(100 \%)$ & $12(86 \%)$ & \\
\hline WHO grade & & & & 0.6 \\
\hline I & $5(15 \%)$ & $2(10 \%)$ & $3(21 \%)$ & \\
\hline II & $25(76 \%)$ & $15(80 \%)$ & $10(72 \%)$ & \\
\hline III & $1(3 \%)$ & $1(5 \%)$ & $0(0 \%)$ & \\
\hline Unknown & $2(6 \%)$ & $1(5 \%)$ & $1(7 \%)$ & \\
\hline Primary tumor site & & & & 0.7 \\
\hline Ventricles & $14(42 \%)$ & $7(37 \%)$ & $7(50 \%)$ & \\
\hline Central & $12(36 \%)$ & $7(37 \%)$ & $5(36 \%)$ & \\
\hline Others & $7(21 \%)$ & $5(26 \%)$ & $2(14 \%)$ & \\
\hline Relapse pattern & & & & 0.4 \\
\hline Yes & $7(21 \%)$ & $3(16 \%)$ & $4(29 \%)$ & \\
\hline No & $26(79 \%)$ & $16(84 \%)$ & $10(71 \%)$ & \\
\hline
\end{tabular}

M, males; F, females. 
From the 19 patients in RT cohort, 15 (79\%) were treated with three-dimensional conformal RT (3D-CRT) and four (21\%) with intensity-modulated radiation therapy (IMRT). The median cumulative RT dose was 54 Gy (range, 50-60 Gy), and it was delivered in 1.8-2 Gy daily fractions. All patients completed the radiation course without RT breaks. Patients were followed regularly every three months with MRI or CT scans to exclude tumor progression. Only two patients $(6 \%)$ received chemotherapy. Common terminology criteria for adverse events (CTCAEs) has been used during and after RT to assess toxicities. Imaging data were reviewed for response assessment according to the recently updated RANO classification of malignant glioma. At the final analysis, two patients had died, while twenty-six were alive, with five patients lost to follow-up.

\section{Statistical Analysis}

All statistical analyses were conducted with SPSS version 27.0 software (IBM, Armonk, NY, USA). Overall survival (OS) was calculated from the first day of RT and progression-free survival (PFS) was calculated from the TT until documented relapse or death. Time-dependent event curves were calculated using the Kaplan-Meier method and were compared using the log-rang test. Differences were considered statistically relevant at a $p$-value $<0.05$.

\section{Results}

Radiotherapy (RT) has been applied in 19 patients (adjuvant RT in 18 patients and salvage RT in two patients). Fourteen patients were only operated without adjuvant therapy. The involved sites included the ventricles (43\%), central (36\%), and other locations (21\%). At time of RT, ten patients had an Eastern Co-operative of Oncology Group (ECOG) score of 0 , seven patients had a score of 1 , and two patients had score of 2 . Sex, tumor location, chemotherapy, RT dose, WHO grades, and Ki67 MIB1 value were equally distributed between RT and non-RT cohorts $(p>0.05)$. However, more patients in the RT group had residual tumors compared with the non-RT group (90\% vs. 50\%, $p=0.02)$. The median follow-up time was 56 months.

\subsection{Overall and Progression-Free Survival Rates}

The 5-year OS and 5-year PFS were $90 \pm 7 \%$ and $76 \pm 11 \%$, respectively. Regarding OS, we could not observe any significant differences between the WHO grades $(p=0.8)$, site of lesion $(p=0.3)$, total resection $(p=0.4)$, chemotherapy administration $(p=0.7)$, intent of radiation $(p=0.4)$, radiation techniques $(p=1)$, and complete response after therapy $(p=0.2)$. However, patients who received RT had a trend towards longer OS than patients who did not $(p=0.09$; Figure 1A). Concerning PFS, there were no significant differences between the WHO grades $(p=0.1)$, site of lesion $(p=0.3)$, total resection $(p=0.7)$, chemotherapy administration $(p=0.6)$, and radiation techniques $(p=1)$. On the other hand, patients who received RT had a significantly longer PFS than patients without RT ( $p=0.004$; Figure 1B), while complete response after therapy was associated with longer PFS $(p=0.07)$. Regarding radiation dose, no PFS or OS differences have been detected $(p>0.05)$.

\subsection{Radiotherapy Toxicities}

RT was well-tolerated without significant adverse events (AEs). However, half of the patients had toxicities (21\% with grade 1 and $32 \%$ with grade 2 AEs). The most common toxicities were partial alopecia, fatigue, and skin redness. Local grade 1 or 2 alopecia and skin changes were described as late RT toxicity in six patients. No patients had grade 3 or 4 AEs. There were no grade 3 or 4 chronic toxicities. 

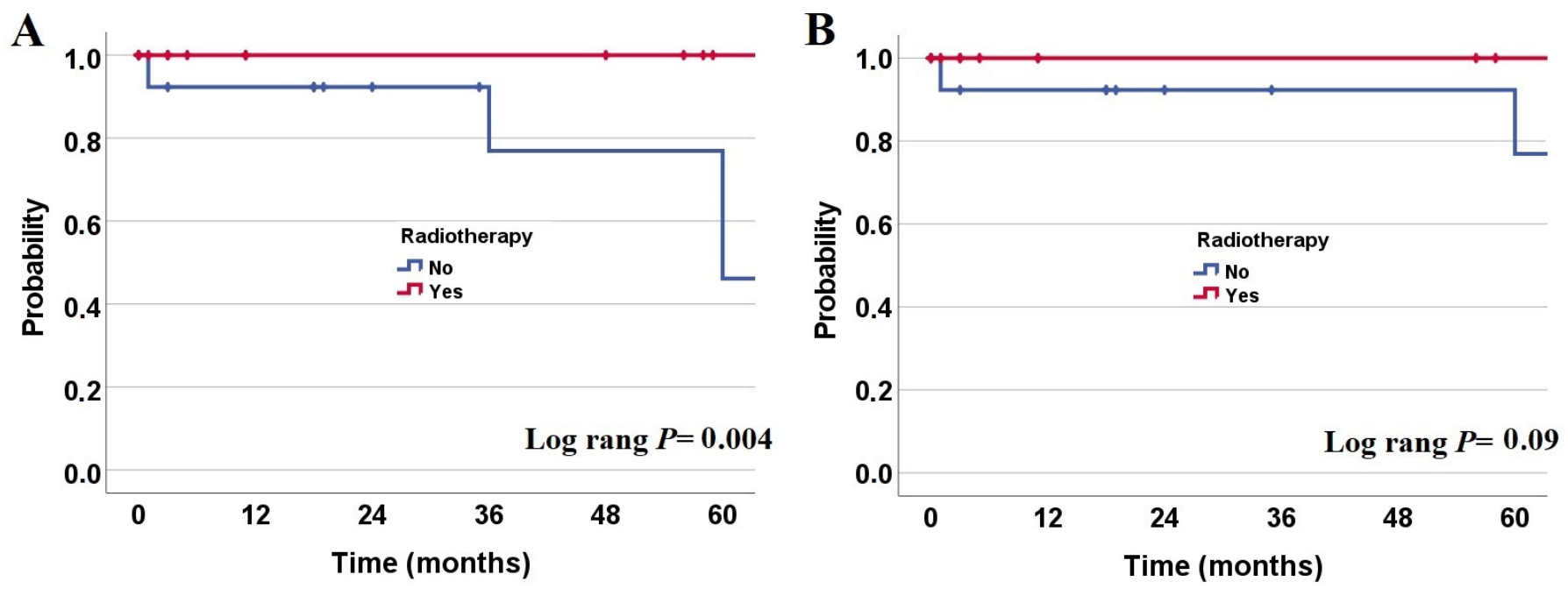

Figure 1. Kaplan-Meier estimate of progression-free survival (A) and overall survival (B) in central neurocytoma patients according to radiotherapy administration $(\mathrm{N}=33)$.

\section{Discussion}

This is an international multicentric analysis that investigated the role of radiotherapy in neurocytoma. Surgery is the standard treatment for NC patients; complete resection is infeasible in locally advanced cancer [9]. RT has a significant effect on PFS and OS, even for tumors with high-risk features, as previously reported by various authors [8].

Several studies, including systematic reviews and meta-analyses, demonstrate a rational indication for RT in recurrent or residual tumors [10-12]. In our study, we focused on the role of fractionated radiotherapy (FCRT), however several studies, including systemic reviews, investigated and compared the results between FCRT and stereotactic radiosurgery (SRS) [13-23]. Therefore, we should balance the benefits and risks of RT. In addition, we should consider that both techniques have over $80-90 \%$ long-term local control rates [14]. However, some of these studies preferred SRS owing to lower toxicities rates and the relative risks of local recurrence. In addition, SRS might reduce the inconvenience and delayed toxicity of FCRT due to its higher conformality and smaller target volume [14]. A literature summary table presenting different radiotherapy techniques for neurocytoma patients is provided (Table 2).

The PFS rate in our study is excellent, even in patients who underwent subtotal resection and adjuvant RT or recurrent RT without surgery. Our study reports a five-year PFS of $76 \%$ and OS reaching $90 \%$, consistent with the previous reports. Tumor location seems to be irrelevant to PFS and OS improvement. In subgroup analysis, we found no significant difference between $\mathrm{WHO}$ grades, lesion site, total resection status, chemotherapy administration, the intent of radiation, and radiation techniques. RT administration correlated significantly with PFS $(p=0.004)$, while complete response after treatment seems to be associated with better PFS $(p=0.07)$. In terms of OS, patients who received radiotherapy had a trend towards longer OS than patients without RT ( $p=0.09)$. However, $90 \%$ of irradiated patients underwent subtotal resection.

The optimal radiation dose for $\mathrm{CN}$ patients was investigated by Rades et al. [9]. In our analysis, most of the patients received a total dose of $54 \mathrm{~Gy}$ and higher doses (>54 Gy) were not associated with better clinical outcomes $(p=0.05)$. Thus, a cumulative dose of 54 Gy may be appropriate for $\mathrm{CN}$ patients regardless of the resection status. 
Table 2. Review of literature.

\begin{tabular}{|c|c|c|c|}
\hline Studies & $\begin{array}{c}\text { Number of Patients } \\
\text { Receiving RT/All Patients }\end{array}$ & $\begin{array}{l}\text { Median } \\
\text { RT Dose in Gy } \\
\text { (Range) }\end{array}$ & Local Control Rate \\
\hline \multicolumn{4}{|c|}{ Fractionated Conventional Radiotherapy (FCRT) } \\
\hline Sharma et al. 1998 [24] & $15 / 15$ & $40-60$ & $100 \%$ \\
\hline Rades et al. 2006 [9] & $177 / 350$ & $50-60$ & $87 \%$ \\
\hline Leenstra et al. 2007 [11] & $18 / 18$ & Median: 54.5 (48.6-61.2) & $78 \%$ \\
\hline Kim et al. 2013 [15] & $7 / 58$ & Median: 54 (50.4-55.8) & $80 \%$ \\
\hline Chen et al. 2014 [25] & $63 / 63$ & Median: 54 (46-60) & $100 \%$ \\
\hline Byun et al. 2018 [26] & $10 / 40$ & $54-56$ & $69 \%$ \\
\hline Current study & $19 / 33$ & Median: 54 (50-60) & $84 \%$ \\
\hline \multicolumn{4}{|c|}{ Stereotactic Radiosurgery (SRS) } \\
\hline Yen et al. 2007 [13] & $6 / 6$ & Median: 15.1 (9-20) & $100 \%$ \\
\hline Kim et al. 2007 [16] & $7 / 13$ & Median: 15.7 (15-18) & $85 \%$ \\
\hline Matsunaga et al. 2010 [17] & $7 / 7$ & Median: 13.9 (12-18) & $88 \%$ \\
\hline Genc et al. 2011 [18] & $18 / 18$ & Median: 16.7 (9-20) & $93 \%$ \\
\hline Karlsson et al. 2012 [19] & $35 / 35$ & Median: 14.0 (11-25) & $83 \%$ \\
\hline Kim et al. 2013 [15] & $17 / 58$ & Median: 16 (9-20) & $80 \%$ \\
\hline Monaco at al. 2015 [14] & $8 / 8$ & Median: 14.6 Gy (12-20) & $87 \%$ \\
\hline
\end{tabular}

RT: radiotherapy; SRS: stereotactic radiosurgery; FCRT: fractionated conventional radiotherapy.

In our study, RT was well-tolerated without significant adverse events. No patients had grade 3 or 4 AEs, in contrast to several studies which showed higher neurological toxicities following treatment [10,27-31]. However, we should also consider the role of surgical resection in developing the side effects, especially late neurotoxicity [32-34]. In the recent EORTC trial, Klein and colleagues [35] proved that memory functioning was not associated with RT target volumes in low-grade glioma patients. Moreover, radiotherapy does not have a deleterious effect on memory function after one year of treatment, compared to chemotherapy.

The role of the MIB-1 labeling index may correlate with prognosis [8,36]. Unfortunately, we could not detect any significant impact of MIB rate on survivals, probably due to the small sample size.

Our study was limited with its retrospective design and limited number, although patient characteristics were reasonably distributed between the examined groups. Moreover, our data agree with previous reports and add to existing literature regarding the importance of RT in this rare disease entity. That being said, a need for international collaboration to create a prospective register is needed to confirm these results further.

\section{Conclusions}

Postoperative RT may to be associated with longer survival rates with an acceptable toxicity profile. However, a larger international prospective analysis is necessary to prove the role of RT.

Author Contributions: Conceptualization, L.S., M.A.M.M., K.E. and H.T.E.; methodology, L.S., M.A.M.M., A.K.H.I., K.E. and H.T.E. software, L.S. and K.E.; validation, L.S., M.A.M.M., K.E. and H.T.E.; formal analysis, L.S. and K.E.; investigation, L.S., A.K.H.I. and K.E.; resources, H.T.E.; data curation: all authors; writing-original draft preparation, K.E. and M.A.M.M.; writing-review and editing, all authors; visualization, L.S. and K.E. and H.T.E.; supervision, H.T.E. and O.M.; 
project administration, H.T.E. and K.E. All authors have read and agreed to the published version of the manuscript.

Funding: This research received no external funding.

Institutional Review Board Statement: All procedures performed in this study were in accordance with the ethical standards of the University Hospital Muenster and the national research committee and with the guidelines of the Helsinki Declaration.

Informed Consent Statement: Informed consent was obtained from all subjects involved in the study.

Data Availability Statement: The data presented in this study are available on request from the corresponding author. The data are not publicly available due to privacy.

Acknowledgments: The authors would like to thank the German Egyptian Social \& Scientific Relationships e. V. (GESR) for the great collaborations.

Conflicts of Interest: The authors declare no conflict of interest.

\section{References}

1. Sharma, M.C.; Deb, P.; Sharma, S.; Sarkar, C. Neurocytoma: A comprehensive review. Neurosurg. Rev. 2006, 29, 270-285, discussion 285. [CrossRef]

2. Hassoun, J.; Gambarelli, D.; Grisoli, F.; Pellet, W.; Salamon, G.; Pellissier, J.F.; Toga, M. Central neurocytoma. An electronmicroscopic study of two cases. Acta Neuropathol. 1982, 56, 151-156. [CrossRef]

3. Louis, D.N.; Perry, A.; Reifenberger, G.; von Deimling, A.; Figarella-Branger, D.; Cavenee, W.K.; Ohgaki, H.; Wiestler, O.D.; Kleihues, P.; Ellison, D.W. The 2016 World Health Organization Classification of Tumors of the Central Nervous System: A summary. Acta Neuropathol. 2016, 131, 803-820. [CrossRef] [PubMed]

4. Hassoun, J.; Söylemezoglu, F.; Gambarelli, D.; Figarella-Branger, D.; von Ammon, K.; Kleihues, P. Central neurocytoma: A synopsis of clinical and histological features. Brain Pathol. 1993, 3, 297-306. [CrossRef]

5. Schmidt, M.H.; Gottfried, O.N.; von Koch, C.S.; Chang, S.M.; McDermott, M.W. Central neurocytoma: A review. J. Neurooncol. 2004, 66, 377-384. [CrossRef]

6. Mackenzie, I.R.A. Central neurocytoma. Cancer 1999, 85, 1606-1610. [CrossRef]

7. Mozes, P.; Szanto, E.; Tiszlavicz, L.; Barzo, P.; Cserhati, A.; Fodor, E.; Hideghety, K. Clinical course of central neurocytoma with malignant transformation-an indication for craniospinal irradiation. Pathol. Oncol. Res. 2014, 20, 319-325. [CrossRef] [PubMed]

8. Vasiljevic, A.; François, P.; Loundou, A.; Fèvre-Montange, M.; Jouvet, A.; Roche, P.-H.; Figarella-Branger, D. Prognostic factors in central neurocytomas: A multicenter study of 71 cases. Am. J. Surg. Pathol. 2012, 36, 220-227. [CrossRef] [PubMed]

9. Rades, D.; Schild, S.E. Treatment recommendations for the various subgroups of neurocytomas. J. Neurooncol. 2006, 77, 305-309. [CrossRef]

10. Hallock, A.; Hamilton, B.; Ang, L.C.; Tay, K.Y.; Meygesi, J.F.; Fisher, B.J.; Watling, C.J.; Macdonald, D.R.; Bauman, G.S. Neurocytomas: Long-term experience of a single institution. Neuro Oncol. 2011, 13, 943-949. [CrossRef] [PubMed]

11. Leenstra, J.L.; Rodriguez, F.J.; Frechette, C.M.; Giannini, C.; Stafford, S.L.; Pollock, B.E.; Schild, S.E.; Scheithauer, B.W.; Jenkins, R.B.; Buckner, J.C.; et al. Central neurocytoma: Management recommendations based on a 35-year experience. Int. J. Radiat. Oncol. Biol. Phys. 2007, 67, 1145-1154. [CrossRef]

12. Lenzi, J.; Salvati, M.; Raco, A.; Frati, A.; Piccirilli, M.; Delfini, R. Central neurocytoma: A novel appraisal of a polymorphic pathology. Our experience and a review of the literature. Neurosurg. Rev. 2006, 29, 286-292. [CrossRef]

13. Yen, C.P.; Sheehan, J.; Patterson, G.; Steiner, L. Gamma knife surgery for neurocytoma. JNS 2007, 107, 7-12. [CrossRef] [PubMed]

14. Monaco, E.A.; Niranjan, A.; Lunsford, L.D. The management of central neurocytoma: Radiosurgery. Neurosurg. Clin. N. Am. 2015, 26, 37-44. [CrossRef]

15. Kim, J.W.; Kim, D.G.; Kim, I.K.; Kim, Y.H.; Choi, S.H.; Han, J.H.; Park, C.-K.; Chung, H.-T.; Park, S.-H.; Paek, S.H.; et al. Central neurocytoma: Long-term outcomes of multimodal treatments and management strategies based on 30 years' experience in a single institute. Neurosurgery 2013, 72, 407-413, discussion 413-414. [CrossRef]

16. Kim, C.-Y.; Paek, S.H.; Jeong, S.S.; Chung, H.-T.; Han, J.H.; Park, C.-K.; Jung, H.-W.; Kim, D.G. Gamma knife radiosurgery for central neurocytoma: Primary and secondary treatment. Cancer 2007, 110, 2276-2284. [CrossRef]

17. Matsunaga, S.; Shuto, T.; Suenaga, J.; Inomori, S.; Fujino, H. Gamma knife radiosurgery for central neurocytomas. Neurol. Med. Chir. 2010, 50, 107-112, discussion 112-113. [CrossRef] [PubMed]

18. Genc, A.; Bozkurt, S.U.; Karabagli, P.; Seker, A.; Bayri, Y.; Konya, D.; Kilic, T. Gamma knife radiosurgery for cranial neurocytomas. J. Neurooncol. 2011, 105, 647-657. [CrossRef] [PubMed]

19. Karlsson, B.; Guo, W.-Y.; Kejia, T.; Dinesh, N.; Pan, D.H.-C.; Jokura, H.; Kawagishi, J.; van Eck, A.T.C.J.; Horstmann, G.A.; Yeo, T.T.; et al. Gamma Knife surgery for central neurocytomas. JNS 2012, 117, 96-101. [CrossRef]

20. Garcia, R.M.; Ivan, M.E.; Oh, T.; Barani, I.; Parsa, A.T. Intraventricular neurocytomas: A systematic review of stereotactic radiosurgery and fractionated conventional radiotherapy for residual or recurrent tumors. Clin. Neurol. Neurosurg. 2014, 117, 55-64. [CrossRef] 
21. Barani, I.J.; Raleigh, D.R.; Larson, D. The management of central neurocytoma: Radiotherapy. Neurosurg. Clin. 2015, 26, 45-56. [CrossRef]

22. Virbel, G.; Cebula, H.; Coca, A.; Lhermitte, B.; Bauchet, L.; Noël, G. Optimisation du choix de la technique d'irradiation des neurocytomes centraux à partir des données de la littérature. Cancer Radiother. 2020, 24, 882-891. [CrossRef]

23. Mahavadi, A.K.; Patel, P.M.; Kuchakulla, M.; Shah, A.H.; Eichberg, D.; Luther, E.M.; Komotar, R.J.; Ivan, M.E. Central Neurocytoma Treatment Modalities: A Systematic Review Assessing the Outcomes of Combined Maximal Safe Resection and Radiotherapy with Gross Total Resection. World Neurosurg. 2020, 137, e176-e182. [CrossRef]

24. Sharlvla, M.C.; Rathore, A.; Karak, A.K.; Sarkar, C. A study of proliferative markers in central neurocytoma. Pathol. 1998, 30, 355-359. [CrossRef] [PubMed]

25. Chen, Y.-D.; Li, W.-B.; Feng, J.; Qiu, X.-G. Long-term outcomes of adjuvant radiotherapy after surgical resection of central neurocytoma. Radiat. Oncol. 2014, 9, 1-8. [CrossRef]

26. Byun, J.; Hong, S.H.; Yoon, M.J.; Kwon, S.M.; Cho, Y.H.; Kim, J.H.; Kim, C.J. Prognosis and treatment outcomes of central neurocytomas: Clinical interrogation based on a single center experience. J. Neuro-Oncol. 2018, 140, 669-677. [CrossRef] [PubMed]

27. Laack, N.N.; Brown, P.D.; Ivnik, R.J.; Furth, A.F.; Ballman, K.V.; Hammack, J.E.; Arusell, R.M.; Shaw, E.G.; Buckner, J.C. Cognitive function after radiotherapy for supratentorial low-grade glioma: A North Central Cancer Treatment Group prospective study. Int. J. Radiat. Oncol. Biol. Phys. 2005, 63, 1175-1183. [CrossRef]

28. Vigliani, M.-C.; Sichez, N.; Poisson, M.; Delattre, J.-Y. A prospective study of cognitive functions following conventional radiotherapy for supratentorial gliomas in young adults: 4-year results. Int. J. Radiat. Oncol. Biol. Phys. 1996, 35, 527-533. [CrossRef]

29. Armstrong, C.L.; Hunter, J.V.; Ledakis, G.E.; Cohen, B.; Tallent, E.M.; Goldstein, B.H.; Tochner, Z.; Lustig, R.; Judy, K.D.; Pruitt, A.; et al. Late cognitive and radiographic changes related to radiotherapy: Initial prospective findings. Neurology 2002, 59, 40-48. [CrossRef]

30. Brown, P.D.; Buckner, J.C.; O’Fallon, J.R.; Iturria, N.L.; Brown, C.A.; O’Neill, B.P.; Scheithauer, B.W.; Dinapoli, R.P.; Arusell, R.M.; Curran, W.J.; et al. Effects of radiotherapy on cognitive function in patients with low-grade glioma measured by the folstein mini-mental state examination. J. Clin. Oncol. 2003, 21, 2519-2524. [CrossRef] [PubMed]

31. Torres, I.J.; Mundt, A.J.; Sweeney, P.J.; Llanes-Macy, S.; Dunaway, L.; Castillo, M.; Macdonald, R.L. A longitudinal neuropsychological study of partial brain radiation in adults with brain tumors. Neurology 2003, 60, 1113-1118. [CrossRef] [PubMed]

32. D'Angelo, V.A.; Galarza, M.; Catapano, D.; Monte, V.; Bisceglia, M.; Carosi, I. Lateral ventricle tumors: Surgical strategies according to tumor origin and development-A series of 72 cases. Neurosurgery 2005, 56, 36-45, discussion 36-45. [CrossRef] [PubMed]

33. Friedman, M.A.; Meyers, C.A.; Sawaya, R. Neuropsychological effects of third ventricle tumor surgery. Neurosurgery 2003, 52, 791-798, discussion 798. [CrossRef]

34. Shi, Z.; Sun, D.; Song, J.; Yao, Y.; Mao, Y. Emotion and cognitive function assessment of patients with central neurocytoma resection through transcortical frontal approach: A 5-year postoperative follow-up study. Chin. Med. J. 2011, 124, 2593-2598.

35. Klein, M.; Drijver, A.J.; van den Bent, M.J.; Bromberg, J.C.; Hoang-Xuan, K.; Taphoorn, M.J.B.; Reijneveld, J.C.; Ben Hassel, M.; Vauleon, E.; Eekers, D.B.P.; et al. Memory in low-grade glioma patients treated with radiotherapy or temozolomide: A correlative analysis of EORTC study 22033-26033. Neuro Oncol. 2021, 23, 803-811. [CrossRef]

36. Söylemezoglu, F.; Scheithauer, B.W.; Esteve, J.; Kleihues, P. Atypical central neurocytoma. J. Neuropathol. Exp. Neurol. 1997, 56, 551-556. [CrossRef] [PubMed] 